\title{
The health service and the general election
}

\author{
Calum R Paton
}

The NHS review was instituted in 1988 in an attempt by Mrs Thatcher's government to divert a debate about alleged underfunding of the service to a debate about efficiency in the provision of health care. It is ironic that, more than three years later, the debate about alleged underfunding has resurfaced in an even more virulent form. Now it seems that the government of John Major is on the defensive, both about alleged underspending on the NHS and about what the media and public perceive as the damaging consequences arising from the implementation of the NHS and Community Care Act.'

Increased public awareness of overt rationing in health care, as purchasing authorities decide what can and cannot be provided by the NHS, has now been joined by a strong public perception that certain of the NHS reforms involve unfairness. There has been much publicity about job losses in some of the first wave of self governing trust hospitals and about the ability of general practices which hold their own budgets to negotiate preferential contracts for their patients.

It is this factor which has allowed the Labour party successfully to attack the government for promoting inequity in access to health care, although recent guidelines on fundholding have gone some way to answer this criticism.

\section{Economic logic}

It is important to examine the reality of the incentives created by allowing two purchasers (district health authorities and general practice fundholders) to contract with providing hospitals and other suppliers of health care. It might be thought that having two purchasers rather than one would fragment the purchasers' bargaining power vis à vis the provider and increase the relative power of the provider in any contract negotiations. To some extent this is true. In the United States a multiplicity of purchasers gives power to providers, even when providers are operating at less than full capacity and when supply may exceed demand in the aggregate. This is, however, only part of the story. For the aggregate money available to purchasers of health care in the United States is huge in absolute and relative terms.

In Britain, however, although latent demand certainly exceeds supply in health care, actual demand expressed by NHS purchasers is limited by the amount of money available to a strictly cash limited NHS. In consequence, there is a limit to the manipulation of the purchaser by the provider. The British hospital provider has to put together a coalition of purchasers, if any sort of market at all is working, in order to attract the required business and break even. As in the United States the relative power of providers and purchasers is determined by two factors - the relative ability to exploit a monopoly position of their own and a competitive position of their opponent, and the relative quantum of supply and demand in aggregate. So in
Britain the hospital may have some bargaining advantage where it can divide and rule among more than one purchaser, but it also has the relative disadvantage that it relies on all or most of the purchasers in order to put together a viable business plan.

One consequence of this, relevant to the current political debate, is that the power of general practitioner purchasers may be overrated. Health authority purchasers, after all, account for markedly more funds, even in areas where general practitioner purchasing is salient. There is nothing to stop a health authority purchaser from threatening to remove business from providers who give preference to general practitioner purchasers. It may be replied that health authority purchasers often rely on their local providers or have an interest in keeping their local providers in business. But this cuts both ways. It is, of course, true that a health authority will not be able to remove all its patients lock, stock, and barrel to another provider. But there is nothing to stop the authority threatening to make contracts elsewhere to a financial total equivalent to the business being offered by the general practitioners in return for their patients jumping the queue or receiving other forms of preferential treatment. It is simply a matter of the purchasers seeking to outdo each other in bargaining vis à vis the provider. This gives the provider some choice, but not unlimited choice where both purchasers must at the end of the day be pleased in some respect. In other words, there is not excess actual demand.

How such theory works out in practice is naturally politically important. What we have here is a series of economic and bargaining incentives which may or may not work out to the advantage of individual patients or indeed of all patients through a better or more efficient health service. Different scenarios can be traced. And in so doing the bureaucratic costs of operating such a market must not be discounted.

\section{Political consequences}

Perhaps more important is the likely political consequence of simply operating such a policy. In Prime Minister's question time on 7 and 9 May Mr Major did not seek to defend the new arrangements by arguing for their beneficial effect (presumably in the long run).$^{34}$ Instead, he sought to play down the notion that any radical change in practice would occur as a result of general practitioner fundholding. That is, in line with the "safety first" policy following the departure of Mrs Thatcher, we are led to believe that the NHS act will not really change all that much. This is surely a political loser for the government. If all the anxiety and, in some cases, tangible fear of inequity are occurring for little purpose and at much bureaucratic and propaganda costs the government surely stands condemned on the grounds of fatuousness.

On the other hand if Mr Major were to be a little bolder and to defend the reforms in the health service more robustly he would be sailing in uncharted waters. 
For example, he might have answered Mr Kinnock by saying,

Yes, we admit that some patients who have clever general practitioners who hold their own budgets may get better or quicker treatment or better facilities during treatment. That is the whole point of the reforms - to allow initiative both by patients and by their advocates, the doctors. Any overall improvement involves differential benefits at first, depending upon who can take advantage first. No rigid bureaucracy can be loosened without such a process. Think of east Europe. Would anyone really have argued for no change there in 1989 on the grounds that there might be some losers, especially temporary ones. Instead, think of the slightly longer term. Patients will become better consumers and doctors will be

\section{If all the anxiety and, in some cases, tangible fear of inequity are occurring for little purpose and at much bureaucratic and propaganda costs the government surely stands condemned on the grounds of fatuousness.}

shopping round for a better deal for their patients when they hold their own budgets. And health authority purchasers will be forced to think of the best ways to protect their patients. So, to talk merely of queue jumping is simply to talk in the language of the past, a static language which doesn't think of improvements through better incentive.

The main problem with this line of reasoning is that it would savour too much of the political style of Mrs Thatcher. In politics generally in Britain at present there is a public mood for safety first and for both consolidation and greater equity in public life following the turmoil of the Thatcher years, especially the latter years when the raft of policy initiatives (including the poll tax) was increasingly out of tune with the public mood. Mr Major would therefore run the serious risk of pleasing the think tanks of the radical right yet losing the election. Such a strategy seems unlikely. What we are therefore left with is the phenomenon of a government moving ahead-on paper - with a series of unpopular reforms, which by the government's own admission and, indeed, design (post-Thatcher) will not make a tremendous amount of difference to health care in the country, save to make it more bureaucratic. This is especially ironic given that the reforms are allegedly market driven.

The Labour party has until recently been on the defensive concerning the policy debate in health care since the white paper was published. This has not stopped it from still being the party most people trust with the health service. It has not in fact needed to be particularly innovative in its thinking concerning the NHS, although recent proposals from the Labour party have shown a willingness to think in terms of how the benefits of planning and yet also sharper economic incentives in the provision of health care can be combined. It is probably fair to say that, in the recent debate, $\mathrm{Mr}$ Kinnock was right by chance. Some of his objections were reasoned; others were merely conservative.

It is silly to alarm the public and mess around with the provision of health care if there are no substantial or even radical policies being pursued to improve the provision of health care. If we really wanted to move to a system whereby consumers choose their general practitioners just as people choose health maintenance organisations in the United States, on the grounds of their ability to deliver good health care at a reasonable price, then general practitioner fundholding on the demand side and opted out hospitals on the supply side might be a good idea. In a British context, however, we have probably come full circle in that such ideas are gradually returning to the right wing think tanks whence they came in the first place.

And the political result is likely to be good for the Labour party as long as health is a salient issue at the election. It is none the less important, from the Labour party's long term point of view, to ensure that taking advantage of the government's misfortune is linked to a strategic plan for the NHS. After all, commitment to quality and to efficiency as well as to equity and effectiveness are cornerstones of Labour's approach to health care in the 1990 s.

\section{The future}

One beneficial aspect of the NHS reforms is, in theory, the ability of the purchasing health authority to determine priorities on behalf of its population and then to achieve these in the most effective and efficient manner possible through negotiation with providers (whether these providers are in its own hospitals or not). Yet one of the recent scandals highlighted by the media has concerned opted out hospitals offering packages of care to purchasing authorities at higher prices in return for prompt treatment-for example, Alder Hey Hospital in Liverpool. Concern over such a phenomenon is justified. There is evidence that short termism and financial opportunism will affect both providers and purchasers and distort health care priorities. In the absence of adequate cost information it is impossible to regulate such a state of affairs, as $\mathrm{Mr}$ Waldegrave promised to do in the House of Commons on 9 May. ${ }^{4}$ Given lack of certainty about costs, it is impossible to know whether hospitals are making unjustified profits or presenting unfair bills to the purchaser.

Moreover, the division of hospitals into self governing trusts and directly managed hospitals still under the direct control of health authorities, which are now schizophrenic in both purchasing and providing, does not help. For trusts are freer to decide their mix of activities and range of prices than directly managed hospitals. This distorts competition.

The fact remains, however, that district health authorities have a responsibility to make decisions on behalf of their citizens concerning the mix of health care activities to be offered within limited budgets. This means that inevitably some districts will have different priorities from others. Thus, someone living in Devon may have less chance of a cataract operation than someone in Manchester, for deliberate as well as accidental reasons based, for example, on inefficiency.

In the prereform NHS waiting lists and times varied widely across the country. Ironically, many of the more optimistic commentators saw in the reforms a chance to tackle this. General practitioners, for example, would have information on where waiting lists were shorter so that they could refer patients in that direction if they were willing to travel. It was only a short step from this to giving the general practitioners their own budgets. The effect on equity was not really discussed at that stage of the reasoning. And it is a perfectly fair point that to improve the overall performance of the service may lead to a disturbance in equity in the sense of equal misery. But in practice general practitioners (without their own budgets) are frequently being prevented from referring to providers where waiting lists are shorter because districts have chosen for financial reasons not to make contracts with these providers.

The challenge faced by those forming an alternative to the government's policy is to diminish dogmatic adherence to market ideology and its concomitant 
denigration of the NHS's great international advantage - capacity for effective planning. Health authorities ought to assess need and then ensure that their providers are attuned to meeting that need through a planning system which offers effective incentives. A

\section{Health authorities ought to assess need and then ensure that their providers are attuned to meeting that need through a planning system which offers incentives.}

courageous policy of this sort is just as likely to meet with conservative opposition as the present government's policy. Labour's recent policy documents represent only the beginning of a strategy. Much work requires to be done, not necessarily before the general election, but truly to improve the NHS.

\section{A successful NHS}

A coherent policy for a successful national health service should include:

(1) Adherence to the principle that money follows the patient but in a manner beneficial to the patient. The NHS act has this policy allegedly as its cornerstone but neglects to mention that a patient's referral has to be sanctioned through a contract before any monetary provision is made for it. In consequence, before the white paper the NHS allowed greater freedom of referral of the patient, although in the absence of adequate finance queues at the doors of the providers often resulted. One of the confusions of the NHS now is that only where patients are registered with fundholding general practitioners can they have at least the possibility of a real freedom of referral plus money following the patient-but even then only for certain limited categories of care, primarily diagnostic services and elective surgery.

(2) Consistency in types of contract placed with providers by general practitioners who hold their own budgets (if this clause is retained in the future) and purchasing health authorities. This will allow the latter to have as much bargaining power as general practitioners. Currently, purchasing health authorities are obliged to place block and cost per volume contracts simply to guarantee the availability of services and an expected volume respectively. The consequence of this is that they have less bargaining power to remove contracts, in order, for example, to try to match the bargaining power of general practitioners, who can act more flexibly. As stated above, the relative scarcity of finance in the NHS allows purchasers to have bargaining power vis à vis providers, even where there is a fragmentation in purchasing. It is important, however, that this bargaining power does not work to the detriment of equity in that patients dependent on different purchasers have different conditions for access.

(3) A citizen's charter, which is a good idea whether in Tory or Labour form. The basic decision has, however, to be taken as to whether the citizen is a consumer-for example, shopping around for different types of purchaser as the luckier United States citizen can shop around for health maintenance organisations or as Dutch citizens, in their new system, can shop around for different types of sickness fund or insurance company or whether the citizens exercise their rights through more collective means. The latter might include guaranteed standards of service, including access to preventive health and health related social services, where national priorities have identified these. The present government has devised a programme of health targets based on recognition of the many social causes of health and ill health. ${ }^{5}$ For these to be meaningful access to health must not be dependent on geographical or chance political factors throughout the country.

(4) A planning system which reconciles incentives for providers to attract business with national priorities based on equity and effectiveness. Instead of a market based contracting system, whether fully operative or merely symbolic, a revitalised planning system can avoid the pitfalls of opting out and fragmentation and confusion in purchasing. Yet it can, with a will, be flexible enough to avoid the bureaucracy and centralism, which has undermined planning in the past, along with planning's subversion to political fads and political bargaining. In other words, planning can coexist with decentralised responsibility in an operational sense to providers.

In more ideological terms a sensible policy for health care will recognise that the health service is a public service where citizens are not merely economic consumers; that economic incentives can be beneficial to providers; and that merely replacing the alleged centralism of planning with the centralism of a government dictated marketplace is futile. Planning guidance for health regions in 1992-3 makes it clear that the NHS Management Executive will police and regulate the pattern of contacts. ${ }^{6}$ The irony for the present government is that, while seeking to distance itself from Thatcherism, it is left clinging halfheartedly to the Thatcherite agenda for the health service. Not all Labour's attacks may be fair to the academic purist, but they are certainly fair as a retort to the confusion and uncertainty shown by immature Conservative policy towards the health service.

1 National health service and community care act 1990. London: HMSO, 1990.

2 NHS Management Executive. foint guidance (NHSME/fCC) to hospital consultants on GP fund holding. London: NHS Management Executive, 1991
(EL(91)94.)

3 Major J. Parliamentary oral answer. House of Commons official report (Hansard) 1991 May 7;190:col 620. (No 102.)

4 Major J. Parliamentary oral answer. House of Commons official report (Hansard) 1991 May 9;190:cols 820-1. (No 104.)

5 Secretaries of State for Health. The health of the nation: a consultative document for health in England. London: HMSO, 1991. (Cmnd 1523.)

6 Brindle D. "Brakes off" market system, but change will start slowly. Guardian 1991 July 25:2
What would be the effect on a polygraph (lie detector) of taking $\beta$ blocking drugs?

A polygraph can record changes in several physiological variables including heart rate, respiration, tremor, and skin impedance. $\beta$ Blockers would attenuate the increase in heart rate that might occur with stress. There is no measurable effect on respiration, except, of course, in patients with asthma. Tremor may be appreciably reduced by $\beta$ blockers. Most non-cardioselective $\beta$ blockers cause peripheral vasoconstriction, but in a double blind crossover placebo controlled study pro- pranolol did not reduce thermal or emotional sweating, ${ }^{1}$ though propranolol at a dose of $160 \mathrm{mg}$ a day for two weeks did diminish skin impedance compared with placebo. ${ }^{2}$ Although a search of published reports failed to find any suggesting that $\beta$ blockers interfere with the result of lie detectors, it is likely that $\beta$ blockers would attenuate the responses, though probably not abolish them altogether. -M D O'BRIEN, physician in nervous diseases, London

1 Allen JA, Lowe D, Rodie IC, Wallace WFM. Studies on sweating in clinical and experimental thyrotoxicosis. Clin Sci 1973;45:765-73.

Ramsay I, Greer S, Bagley C. Propranolol in neurotic and thyrotoxic anxiety. Br f Psychiatry 1973;122:555-60. 